\title{
PERSEPSI MASYARAKAT TERHADAP PENGELOLAAN HUTAN MANGROVE DI DESA TIWOHO KECAMATAN WORI KABUPATEN MINAHASA UTARA PROVINSI SULAWESI UTARA
}

\author{
Vina S. Sondakh'; Siti Suhaeni²; Vonne Lumenta ${ }^{2}$ \\ 1)Mahasiswa Fakultas Perikanan dan IImu Kelautan Universitas Sam Ratulangi Manado \\ 2)Staff Pengajar Fakultas Perikanan dan IImu Kelautan Universitas Sam Ratulangi Manado \\ Koresponden email : vinasondakh@yahoo.com
}

\begin{abstract}
The purpose of this study is to examine the Tiwoho Village community wather the already knows and understand the function and benefits of the mangrove forests management. The basic method of this research is survey. The sample are taken 35 people or $15 \%$ of 691 total population by using the purposive sampling method. Data collected data are primary and secondary data. Analysis data using the Gutman scale, while to determine the perception of Tiwoho community are used the Likert Scale. The results shows the community skill known that the function and benefit of the mangrove forest in Tiwoho Village are the very good reached 95\% and 5\% people didn't know. The excellent public skill are cooperative the active role of local government in socializing mangrove forests. The perception of Tiwoho Village community on mangrove forest management assessed based on 10 criteria, almost all of communitas had good perception include a positive range. There is one criteria has very good in positive perception agree that mangrove forest management working on community development in collaboration with government and the private role.
\end{abstract}

Keywords: Tiwoho village, mangrove forest, perception.

\begin{abstract}
Abstrak
Tujuan penelitian ini adalah untuk mengkaji apakah masyarakat mengetahui, mengerti tentang fungsi dan manfaat hutan mangrove serta untuk mengetahui persepsi masyarakat Desa Tiwoho terhadap pengelolaan hutan mangrove. Metode dasar penelitian ini adalah survey. Jumlah populasi sebanyak 691 orang, sampel yang diambil sebanyak 35 orang atau $5 \%$ dari jumlah populasi dengan menggunakan metode purposive sampling. Data yang dikumpulkan adalah data primer dan data sekunder. Analisis data menggunakan skala Gutman, sedangkan untuk mengetahui persepsi masyarakat menggunakan skala Likert. Berdasarkan hasil analisis diketahui bahwa pengetahuan masyarakat terhadap fungsi dan manfaat hutan mangrove yang ada di Desa Tiwoho $95 \%$ sangat baik, hanya $5 \%$ masyarakat yang kurang mengetahui fungsi dan manfaat hutan mangrove. Pengetahuan masyarakat yang sangat baik tentang fungsi dan manfaat hutan mangrove, ini tidak terlepas dari peran aktif pemerintah setempat dan tokoh masyarakat dalam mensosialisasikan fungsi dan manfaat hutan mangrove. Persepsi masyarakat Desa Tiwoho terhadap pengelolaan hutan mangrove yang dinilai berdasarkan 10 kriteria hampir semua masyarakat mempunyai persepsi baik dan termasuk dalam rentang yang positif. Ada salah satu kriteria yang mempunyai persepsi sangat baik dan sangat positif dari masyarakat, mereka sangat setuju kalau pengelolaan hutan mangrove bukan saja merupakan tanggung jawab pemerintah melainkan tanggung jawab bersama, baik pemerintah, swasta maupun masyarakat.
\end{abstract}

Kata kunci: Desa Tiwoho, hutan mangrove, persepsi.

\section{PENDAHULUAN}

Hutan mangrove merupakan

sumberdaya alam hayati yang mempunyai berbagai keragaman potensi yang memberikan manfaat bagi kehidupan manusia baik secara langsung maupun tidak langsung dan bisa dirasakan, baik oleh masyarakat yang tinggal di dekat kawasan hutan mangrove maupun masyarakat yang tinggal jauh dari kawasan hutan mangrove (Kustanti, 2011). Keberadaan hutan mangrove dapat memberikan berbagai manfaat, di antaranya sebagai stabilitator kondisi pantai, mencegah terjadinya abrasi dan intrusi air laut, sebagai sumber keanekaragaman biota akuatik dan non-akuatik, sebagai sumber bahan yang dapat dikonsumsi masyarakat dan lain sebagainya (Yuliasamaya dkk., 2014).

Bagi masyarakat pesisir, ekosistem mangrove berperan penting dalam menopang kehidupan mereka, 
baik dari aspek ekonomi maupun ekologi. Pada aspek ekonomi, mangrove digunakan untuk arang, kayu bakar dan tempat penangkapan berbagai jenis ikan, udang dan kepiting, dll. Sedangkan dari segi ekologis, ekosistem mangrove berfungsi sebagai sumber makanan penting untuk invertebrata kecil, mangrove juga berperan sebagai makanan bagi hewan yang lebih besar. Ekosistem mangrove juga merupakan daerah asuhan (nursery ground) bagi ikan dan kerang-kerangan (Hussain dan Badola dalam Setiawan dkk., 2017).

Persepsi secara umum sering diartikan sebagai cara pandang masyarakat atau seseorang terhadap suatu obyek, baik itu obyek fisik maupun sosial. Menurut Pahlevi (2007), persepsi adalah suatu proses untuk membuat penilaian (judgment) atau membangun kesan (impression) mengenai berbagai macam hal yang terdapat di dalam lapangan penginderaan seseorang. Sikap adalah kesiapan, kesediaan untuk bereaksi terhadap suatu objek, jadi masih berupa kecenderungan dalam bertindak demi seseorang (Rahayu, 2010). Sikap sangat menentukan perilaku dan tanggapan seseorang terhadap masalah kemasyarakatan serta masalah lingkungan. Sumberdaya di alam tidak dapat dilestarikan dan dikelola dengan baik tanpa terlebih dahulu mengetahui persepsi dan sikap masyarakat terhadap lingkungan (Lee and Zhang dalam Setiawan dkk., 2017).

Salah satu ekosistem mangrove di Provinsi Sulawesi Utara berada di Desa Tiwoho Kecamatan Wori Kabupaten Minahasa Utara. Desa Tiwoho merupakan salah satu daerah yang memiliki kawasan hutan mangrove yang cukup luas sebesar $\pm 62,502$ ha. Keberadaan kawasan hutan mangrove ini sudah ada sejak sebelum desa ini terbentuk dan sebagai sumber mata pencaharian bagi masyarakat sekitar hutan mangrove (Kalitouw dkk., 2015). Mengetahui persepsi dan sikap masyarakat terhadap sumber daya alam akan sangat membantu untuk merancang strategi pengelolaan yang efektif, menjaga agar sumberdaya alam tetap lestari dan dapat memenuhi kebutuhan hidup masyarakat setempat (Dolisca dalam Setiawan dkk., 2017). Jika seluruh sikap dan perilaku yang dilakukan masyarakat bersifat negatif, maka dukungan terhadap upaya pengelolaan hutan mangrove akan rendah.

\section{METODE PENELITIAN}

Metode yang digunakan dalam penelitian ini adalah metode survei. Menurut Sugiyono (2013). Metode survei adalab metode yang digunakan untuk mendapatkan data dari tempat tertentu yang alamiah bukan buatan. Jumlah populasi yang ada sebanyak 691 orang, sampel yang diambil sebanyak 35 orang atau $5 \%$ dari jumlah populasi.

$$
\text { Pengambilan }
$$
sampel menggunakan metode purposive sampling yaitu salah satu teknik sampling non random sampling dan menentukan pengambilan sampel dengan cara menetapkan ciri-ciri khusus yang sesuai dengan tujuan penelitian agar sampel yang diambil nantinya dapat memenuhi kriteria-kriteria yang mendukung atau sesuai dengan penelitian, kriteria dalam penelitian ini adalah jenis pekerjaan.

Teknik pengumpulan data yang digunakan dalam penelitian ini adalah: Observasi, yaitu meliputi melakukan pencatatan secara sistematik kejadiankejadian, perilaku, objek-objek yang dilihat dan hal-hal lain yang diperlukan dalam mendukung penelitian yang 
sedang dilakukan (Sarwono, 2009). Observasi yang dilakukan adalah melihat langsung di lokasi penelitian dan kuisioner, yaitu menggunakan angket atau kuesioner merupakan teknik pengumpulan data yang dilakukan dengan cara memberi seperangkat pertanyaan atau pernyataan tertulis kepada responden untuk dijawab. Kuisioner dalam penelitian ini digunakan sebagai panduan dalam mewawancarai responden untuk mengetahui Presepsi Masyarakat Terhadap Pengelolaan Hutan Mangrove di Desa Tiwoho Kecamatan Wori Kabupaten Minahasa Utara Provinsi Sulawesi Utara.

Instrumen dalam penelitian ini digunakan untuk mengukur variabel yang diteliti. Skala pengukuran merupakan seperangkat aturan yang diperlukan untuk mengkuantitatifkan data dari pengukuran suatu variabel, dan untuk mencapai tujuan pertama menggunakan skala Guttman. Dari skala ini diperoleh jawaban yang tegas yaitu ya - tidak; benar - salah; pernah- tidak pernah; positif - negatif, dll. Tujuan kedua dicapai dengan menggunakan skala Likert. Skala ini digunakan untuk mengukur sikap, pendapat dan persepsi seseorang atau sekelompok orang tentang fenomena sosial (Sugiyono, 1994).

\section{HASIL DAN PEMBAHASAN}

\section{Pengetahuan Masyarakat Terhadap Fungsi dan Manfaat Mangrove}

Pengetahuan

masyarakat terhadap fungsi dan manfaat mangrove merupakan penilaian pemahaman masyarakat tentang ekosistem mangrove yang ada di Desa Tiwoho. Berdasarkan hasil penelitian yang dianalisis dengan skala Gutman dapat disimpulkan bahwa pengetahuan masyarakat terhadap fungsi dan manfaat mangrove yang ada di Desa Tiwoho sangat baik dapat dilihat pada Tabel 1 .

\section{Pengetahuan Masyarakat Terhadap} Fungsi dan Manfaat Mangrove

Pengetahuan

masyarakat terhadap fungsi dan manfaat mangrove merupakan penilaian pemahaman masyarakat tentang ekosistem mangrove yang ada di Desa Tiwoho. Berdasarkan hasil penelitian yang dianalisis dengan skala Gutman dapat disimpulkan bahwa pengetahuan masyarakat terhadap fungsi dan manfaat mangrove yang ada di Desa Tiwoho sangat baik dapat dilihat pada Tabel 1 .

Tabel 1. Hasil Analisis Skala Gutman

\begin{tabular}{|c|c|c|c|c|c|c|}
\hline Indikator & $\mathrm{Ya}$ & $\%$ & Tidak & $\%$ & Rataan Ya (\%) & Rataan Tidak (\%) \\
\hline 10 & 35,00 & 100,00 & 0,00 & 0,00 & \multirow{12}{*}{94,86} & \multirow{12}{*}{5,14} \\
\hline 2 & 35,00 & 100,00 & 0,00 & 0,00 & & \\
\hline 3 & 35,00 & 100,00 & 0,00 & 0,00 & & \\
\hline 4 & 35,00 & 100,00 & 0,00 & 0,00 & & \\
\hline 5 & 35,00 & 100,00 & 0,00 & 0,00 & & \\
\hline 6 & 35,00 & 100,00 & 0,00 & 0,00 & & \\
\hline 7 & 35,00 & 100,00 & 0,00 & 0,00 & & \\
\hline 8 & 35,00 & 100,00 & 0,00 & 0,00 & & \\
\hline 9 & 35,00 & 100,00 & 0,00 & 0,00 & & \\
\hline 10 & 28,00 & 80,00 & 7,00 & 20,00 & & \\
\hline 11 & 28,00 & 80,00 & 7,00 & 20,00 & & \\
\hline 12 & 24,00 & 68,57 & 11,00 & 31,43 & & \\
\hline
\end{tabular}




\begin{tabular}{|c|c|c|c|c|c|c|}
\hline Indikator & $\mathrm{Ya}$ & $\%$ & Tidak & $\%$ & Rataan Ya (\%) & Rataan Tidak (\%) \\
\hline 13 & 24,00 & 68,57 & 11,00 & 31,43 & & \\
\hline 14 & 35,00 & 100,00 & 0,00 & 0,00 & & \\
\hline 15 & 35,00 & 100,00 & 0,00 & 0,00 & & \\
\hline 16 & 35,00 & 100,00 & 0,00 & 0,00 & & \\
\hline 17 & 35,00 & 100,00 & 0,00 & 0,00 & & \\
\hline 18 & 35,00 & 100,00 & 0,00 & 0,00 & & \\
\hline 19 & 35,00 & 100,00 & 0,00 & 0,00 & & \\
\hline 20 & 35,00 & 100,00 & 0,00 & 0,00 & & \\
\hline
\end{tabular}

Sumber: Data primer diolah, 2019

Responden memiliki pemahaman yang baik tentang mangrove, hal ini terlihat dari Tabel 1 yang merupakan hasil analisis skala Guttman, diketahui bahwa responden rata-rata menyatakan mengetahui dan paham akan fungsi dan manfaat hutan mangrove, mereka yang menyatakan itu sebesar $94,857 \%$, dan mereka yang menyatakan kurang mengetahui dan kurang paham akan fungsi dan manfaat hutan mangrove hanya $5,143 \%$.

Pengetahuan dan pemahaman masyarakat Desa Tiwoho tentang fungsi dan manfaat hutan mangrore yang sangat baik ini tidak terlepas dari peran aktif pemerintah dan tokoh masyarakat yang ada dalam mensosialisasikan fungsi dan manfaat hutan mangrove pada setiap kesempatan. Sosialisasi oleh pemerintah setempat beserta tokoh masyarakat dilakukan hampir di setiap kesempatan. Sosialisasi tentang mangrove ini juga diberikan pada anakanak sekolah, hal ini dibuktikan dengan adanya mata pelajaran khusus tentang mangrove sebagai muatan lokal.

Berdasarkan hasil analisis hanya $5,143 \%$ yang kurang mengetahui dan kurang paham akan fungsi dan manfaat hutan mangrove terutama tentang sedimentasi dan abrasi, hal ini karena bahasanya yang terasa asing bagi telinga mereka sehingga tidak mudah diingat.

\section{Persepsi Masyarakat}

Terdapat sepuluh kriteria pernyataan yang digunakan untuk mengukur persepsi masyarakat terhadap pengelolaan hutan mangrove yang ada di Desa Tiwoho. Berdasarkan hasil analisis dengan menggunakan skala Likert diperoleh hasil seperti terlihat pada Tabel 2, sebagai berikut:

Tabel 2. Hasil Analisis Skala Likert

\begin{tabular}{|c|c|c|c|c|c|c|c|c|c|c|c|c|c|}
\hline \multirow{2}{*}{ Dimensi } & \multirow{2}{*}{ Indikator } & Skor 1 & & Skor 2 & & Skor 3 & & Skor & & Skor 5 & & \multirow{2}{*}{$\begin{array}{l}\text { Rataan } \\
\text { Indikator }\end{array}$} & \multirow{2}{*}{$\begin{array}{c}\text { Rataan } \\
\text { Dimensi }\end{array}$} \\
\hline & & $F$ & $\%$ & $F$ & $\%$ & $f$ & $\%$ & $F$ & $\%$ & $F$ & $\%$ & & \\
\hline \multirow{5}{*}{$X_{1}$} & $X_{11}$ & 6 & 17,14 & 11 & 31,43 & 4 & 11,43 & 9 & 25,71 & 5 & 14,29 & 2,89 & \multirow{5}{*}{3,18} \\
\hline & $X_{12}$ & 10 & 28,57 & 8 & 22,86 & 7 & 20,00 & 6 & 17,14 & 4 & 11,43 & 2,60 & \\
\hline & $X_{13}$ & 8 & 22,86 & 14 & 40,00 & 2 & 5,71 & 6 & 17,14 & 5 & 14,29 & 2,60 & \\
\hline & $X_{14}$ & 3 & 8,57 & 6 & 17,14 & 4 & 11,43 & 12 & 34,29 & 10 & 28,57 & 3,57 & \\
\hline & $X_{15}$ & 3 & 8,57 & 7 & 20,00 & 1 & 2,86 & 16 & 45,71 & 8 & 22,86 & 4,26 & \\
\hline \multirow{5}{*}{$X_{2}$} & $X_{21}$ & 2 & 5,71 & 3 & 8,57 & 0 & 0 & 14 & 40,00 & 16 & 45,72 & 4,11 & \multirow{5}{*}{3,81} \\
\hline & $X_{22}$ & 2 & 5,71 & 4 & 11,43 & 6 & 17,14 & 15 & 42,86 & 8 & 22,86 & 3,66 & \\
\hline & $X_{23}$ & 1 & 2,86 & 8 & 22,86 & 3 & 8,57 & 14 & 40,00 & 9 & 25,71 & 3,63 & \\
\hline & $X_{24}$ & 4 & 11,43 & 7 & 20,00 & 0 & 0 & 11 & 31,43 & 13 & 37,14 & 3,63 & \\
\hline & $\mathrm{X}_{25}$ & 2 & 5,71 & 5 & 14,29 & 0 & 0 & 12 & 34,29 & 16 & 45,71 & 4,00 & \\
\hline \multirow{3}{*}{$X_{3}$} & $X_{31}$ & 2 & 5,71 & 10 & 28,57 & 3 & 8,57 & 11 & 31,43 & 9 & 25,72 & 3,43 & \multirow{3}{*}{3,61} \\
\hline & $X_{32}$ & 3 & 8,57 & 12 & 34,29 & 2 & 5,71 & 10 & 28,57 & 8 & 22,86 & 3,23 & \\
\hline & $X_{33}$ & 1 & 2,86 & 2 & 5,71 & 4 & 11,43 & 12 & 34,29 & 16 & 45,71 & 4,14 & \\
\hline
\end{tabular}




\begin{tabular}{|c|c|c|c|c|c|c|c|c|c|c|c|c|c|}
\hline & & Skor 1 & & Skor 2 & & Skor 3 & & Skor 4 & & Skor 5 & & \begin{tabular}{|l|} 
Rataan \\
\end{tabular} & Rataan \\
\hline Dimensı & Indikator & $F$ & $\%$ & $F$ & $\%$ & $f$ & $\%$ & $F$ & $\%$ & $F$ & $\%$ & Indikator & Dimens \\
\hline & $X_{34}$ & 2 & 5,71 & 3 & 8,57 & 5 & 14,29 & 15 & 42,86 & 10 & 28,57 & \begin{tabular}{|l|}
3,80 \\
\end{tabular} & \\
\hline & $X_{35}$ & 4 & 11,43 & 4 & 11,43 & 6 & 17,14 & 13 & 37,14 & 8 & 22,86 & 3,49 & \\
\hline \multirow{5}{*}{$X_{4}$} & $X_{41}$ & 1 & 2,86 & 3 & 8,57 & 7 & 20,00 & 11 & 31,43 & 13 & 37,14 & 3,91 & \multirow{5}{*}{3,76} \\
\hline & $X_{42}$ & 5 & 14,29 & 7 & 20,00 & 3 & 8,57 & 13 & 37,14 & 7 & 20,00 & 3,26 & \\
\hline & $X_{43}$ & 0 & 0 & 0 & 0 & 0 & 0 & 17 & 48,57 & 18 & 51,43 & 4,51 & \\
\hline & $X_{44}$ & 6 & 17,14 & 8 & 22,86 & 2 & 5,71 & 10 & 28,57 & 9 & 25,72 & 3,23 & \\
\hline & $X_{45}$ & 8 & 22,86 & 11 & 31,43 & 0 & 0 & 9 & 25,71 & 7 & 20,00 & 3,89 & \\
\hline \multirow{5}{*}{$X_{5}$} & $X_{51}$ & 3 & 8,57 & 9 & 25,71 & 8 & 22,86 & 10 & 28,57 & 5 & 14,29 & 3,14 & \multirow{5}{*}{3,46} \\
\hline & $X_{52}$ & 6 & 17,14 & 12 & 34,28 & 5 & 14,29 & 5 & 14,29 & 7 & 20,00 & 2,86 & \\
\hline & $X_{53}$ & 2 & 5,71 & 4 & 11,43 & 7 & 20,00 & 13 & 37,14 & 9 & 25,72 & 3,66 & \\
\hline & $X_{54}$ & 3 & 8,57 & 6 & 17,14 & 5 & 14,29 & 10 & 28,57 & 11 & 31,43 & 3,57 & \\
\hline & $X_{55}$ & 0 & 0 & 2 & 5,71 & 6 & 17,14 & 15 & 42,86 & 12 & 34,29 & 4,06 & \\
\hline \multirow{5}{*}{$X_{6}$} & $X_{61}$ & 3 & 8,57 & 3 & 8,57 & 4 & 11,43 & 11 & 31,43 & 14 & 40,00 & 3,86 & \multirow{5}{*}{4,01} \\
\hline & $X_{62}$ & 2 & 5,71 & 3 & 8,57 & 6 & 17,14 & 9 & 25,72 & 15 & 42,86 & 3,91 & \\
\hline & $X_{63}$ & 2 & 5,71 & 4 & 11,43 & 5 & 14,29 & 13 & 37,14 & 11 & 31,43 & 3,77 & \\
\hline & $X_{64}$ & 1 & 2,86 & 2 & 5,71 & 4 & 11,43 & 12 & 34,29 & 16 & 45,71 & 4,14 & \\
\hline & $X_{65}$ & 0 & 0 & 0 & 0 & 4 & 11,43 & 14 & 40,00 & 17 & 48,57 & 4,37 & \\
\hline \multirow{5}{*}{$X_{7}$} & $X_{71}$ & 2 & 5,71 & 7 & 20,00 & 6 & 17,14 & 11 & 31,43 & 9 & 25,72 & 3,51 & \multirow{5}{*}{3,87} \\
\hline & $X_{72}$ & 0 & 0 & 0 & 0 & 0 & 0 & 14 & 40,00 & 21 & 60,00 & 4,60 & \\
\hline & $\mathrm{X}_{73}$ & 2 & 5,71 & 4 & 11,43 & 10 & 28,57 & 12 & 34,29 & 7 & 20,00 & 3,51 & \\
\hline & $\mathrm{X}_{74}$ & 0 & 0 & 4 & 11,43 & 6 & 17,14 & 10 & 28,57 & 15 & 42,86 & 4,03 & \\
\hline & $X_{75}$ & 1 & 2,86 & 3 & 8,57 & 12 & 34,28 & 8 & 22,86 & 11 & 31,43 & 3,71 & \\
\hline \multirow{5}{*}{$X_{8}$} & $X_{81}$ & 2 & 5,71 & 5 & 14,29 & 3 & 8,57 & 11 & 31,43 & 14 & 40,00 & 3,86 & \multirow{5}{*}{3,91} \\
\hline & $X_{82}$ & 1 & 2,86 & 2 & 5,71 & 3 & 8,57 & 16 & 45,72 & 13 & 37,14 & 4,09 & \\
\hline & $\mathrm{X}_{83}$ & 2 & 5,71 & 3 & 8,57 & 6 & 17,14 & 10 & 28,58 & 14 & 40,00 & 3,89 & \\
\hline & $X_{84}$ & 2 & 5,71 & 4 & 11,43 & 5 & 14,29 & 13 & 37,14 & 11 & 31,43 & 3,77 & \\
\hline & $X_{85}$ & 1 & 2,86 & 3 & 8,57 & 4 & 11,43 & 15 & 42,86 & 12 & 34,28 & 3,97 & \\
\hline \multirow{5}{*}{$X_{9}$} & $X_{91}$ & 2 & 5,71 & 5 & 14,29 & 9 & 25,71 & 12 & 34,29 & 7 & 20,00 & 3,49 & \multirow{5}{*}{3,56} \\
\hline & $X_{92}$ & 2 & 5,71 & 4 & 11,43 & 6 & 17,14 & 13 & 37,15 & 10 & 28,57 & 3,71 & \\
\hline & $X_{93}$ & 3 & 8,57 & 3 & 8,57 & 8 & 22,86 & 11 & 31,43 & 10 & 28,57 & 3,63 & \\
\hline & $X_{149}$ & 3 & 8,57 & 4 & 11,43 & 7 & 20,00 & 12 & 34,29 & 9 & 25,71 & 3,57 & \\
\hline & $X_{95}$ & 3 & 8,57 & 6 & 17,14 & 8 & 22,86 & 10 & 28,57 & 8 & 22,86 & 3,40 & \\
\hline \multirow{5}{*}{$X_{10}$} & $X_{101}$ & 0 & 0 & 0 & 0 & 4 & 11,43 & 17 & 48,57 & 14 & 40,00 & 4,29 & \multirow{5}{*}{3,84} \\
\hline & $X_{102}$ & 0 & 0 & 0 & 0 & 6 & 17,14 & 16 & 45,72 & 13 & 37,14 & 4,20 & \\
\hline & $X_{103}$ & 2 & 5,71 & 5 & 14,29 & 8 & 22,86 & 11 & 31,43 & 9 & 25,71 & 3,57 & \\
\hline & $X_{104}$ & 2 & 5,71 & 3 & 8,57 & 14 & 40,00 & 9 & 25,72 & 7 & 20,00 & 3,46 & \\
\hline & $X_{105}$ & 3 & 8,57 & 3 & 8,57 & 7 & 20,00 & 12 & 34,29 & 10 & 28,57 & 3,66 & \\
\hline
\end{tabular}

Sumber: Data primer diolah, 2019

\section{Persepsi: Kerusakan Hutan Mangrove Karena Faktor Alam}

Berdasarkan hasil analisis dengan menggunakan skala Likert tentang kerusakan hutan mangrove karena faktor alam diperoleh skor rataan dimensinya sebesar 3,18 , berarti responden mempunyai persepsi yang baik dan setuju dengan pernyataan tersebut. Hal ini dirasakan oleh masyarakat bahwa secara fisik ada perubahan pasang surut sehingga ketinggian ombak dan derasnya arus juga berubah, musim yang mulai berubah dan tidak menentu merupakan gangguan alam, hal ini menjadi faktor yang merusak mangrove.

2. Persepsi: Kerusakan Hutan Mangrove Karena Perbuatan Manusia

Berdasarkan hasil analisis dengan menggunakan skala Likert tentang kerusakan hutan mangrove karena perbuatan manusia diperoleh skor rataan dimensinya sebesar 3,81 . Hal ini berarti responden mempunyai persepsi yang baik dan 
setuju dengan pernyataan tersebut. Kerusakan hutan mangrove selain karena faktor alam juga karena ulah manusia, seperti penebangan liar pembuatan tambak, pembangunan tempat wisata di pinggir pantai dan kurangnya minat masyarakat menanam pohon mangrove juga rendahnya minat masyarakat memelihara pohon mangrove dan lain-lain. Persepsi masyarakat terhadap pernyataan ini berada pada rentang yang positif.

3. Persepsi: Kerusakan Hutan Mangrove Karena Kepentingan Ekonomi

Berdasarkan hasil analisis dengan menggunakan skala Likert tentang kerusakan hutan mangrove karena adanya kepentingan ekonomi diperoleh skor rataan dimensinya sebesar 3,61, berarti responden mempunyai persepsi yang baik dan setuju dengan pernyataan tersebut. Kerusakan hutan mangrove disebabkan karena adanya kepentingan ekonomi kebanyakan seperti adanya pembuatan hotel di pinggir pantai, pembuatan pusat perbelanjaaan di pinggir pantai, konversi hutan mangrove menjadi tempat wisata, reklamasi pantai dan juga usaha tambak.

4. Persepsi: Mangrove Mempunyai Manfaat Penting Bagi Lingkungan Pesisir

Berdasarkan hasil analisis dengan menggunakan skala Likert tentang mangrove yang mempunyai manfaat penting bagi lingkungan pesisir, diperoleh skor rataan dimensinya sebesar 3,76. Hal ini berarti responden mempunyai persepsi yang baik dan setuju dengan pernyataan tersebut. Masyarakat pesisir merasakan manfaat hutan mangrove karena dapat menahan abrasi, membuat hijau pemandangan, mengurangi panas dan dapat dijadikan kayu bakar serta bahan bangunan. Persepsi masyarakat terhadap pernyataan ini berada pada rentang yang positif, responden juga menyatakan perlu adanya pemeliharaan hutan mangrove untuk menjaga kelestariannya.

5. Persepsi: Mangrove Mempunyai Manfaat Penting Bagi Kegiatan Tambak

Berdasarkan hasil analisis dengan menggunakan skala Likert tentang mangrove yang mempunyai manfaat penting bagi kegiatan tambak, diperoleh skor rataan dimensinya sebesar 3,46. Hal ini berarti responden mempunyai persepsi yang baik dan setuju dengan pernyataan tersebut. Responden menyatakan ini karena adanya pengalaman di Desa Tiwoho yang sebagian lahan hutan mangrove pernah dikonversikan menjadi tambak udang beberapa waktu yang lalu. Dengan demikian mereka mengetahui bahwa mangrove sangat bermanfaat bagi usaha tambak.

6. Persepsi: Pengelolaan Mangrove Merupakan Tanggung Jawab Bersama

Berdasarkan hasil analisis dengan menggunakan skala Likert tentang pengelolaan mangrove merupakan tanggung jawab bersama diperoleh skor rataan yang dimensinya sebesar 4,01. Hal ini berarti responden mempunyai persepsi yang sangat baik dan sangat setuju dengan pernyataan tersebut. Masyarakat sadar bahwa pengelolaan hutan mangrove bukan 
hanya tanggung jawab pemerintah, Dinas Kehutanan atau KKP dan bukan pula hanya tanggung jawab laki-laki saja tetapi merupakan tanggung jawab bersama. Persepsi masyarakat terhadap pernyataan ini berada pada rentang yang sangat positif. Responden menyatakan bahwa dalam pengelolaan hutan mangrove yang ada di Desa Tiwoho, masyarakat dilibatkan bersama pemerintah daerah, pihak swasta, LSM dan organisasi keagamaan.

7. Persepsi: Penegakan Hukum Lingkungan Dinilai Sudah Cukup memadai

Berdasarkan hasil analisis dengan menggunakan skala Likert tentang penegakan hukum lingkungan yang dinilai sudah cukup memadai diperoleh skor rataan dimensinya sebesar 3,87, berarti responden mempunyai persepsi yang baik dan setuju dengan pernyataan tersebut. Masyarakat merasa penegakan hukum lingkungan dinilai sudah cukup memadai karena pelaku penebangan liar pohon mangrove mendapat hukuman. Hukum berlaku bagi siapa saja tanpa pandang bulu terhadap o pelaku perusakan ekosistem mangrove. Hal ini terbukti karena di Desa Tiwoho juga berlaku hukum bagi yang menebang pohon mangrove harus menanam 10 kali lebih banyak dari yang ditebang, sehingga masyarakat percaya penegakan hukum lingkungan tidak tebang pilih. Persepsi masyarakat terhadap pernyataan ini berada pada rentang yang positif.

8. Persepsi: Partisipasi Masyarakat Dalam Pelestarian Hutan Mangrove Meningkat
Berdasarkan hasil analisis dengan menggunakan skala Likert tentang partisipasi masyarakat dalam pelestarian hutan mangrove meningkat, diperoleh skor rataan dimensinya sebesar 3,91 , berarti responden mempunyai persepsi yang baik dan setuju bahkan cenderung sangat baik dan sangat setuju dengan pernyataan tersebut karena skornya hampir 4. Partisipasi masyarakat dalam pelestarian hutan mangrove meningkat karena minat masyarakat untuk menanam pohon mangrove dan memelihara pohon mangrove juga meningkat. Hal ini dikarenakan kesadaran masyarakat terhadap lingkungan meningkat dan kesadaran masyarakat terhadap fungsi dan manfaat adanya hutan mangrove juga meningkat. Persepsi masyarakat terhadap pernyataan ini berada pada rentang yang positif.

9. Persepsi:

Kelembagaan

Berpartisipasi Dalam Pelestarian Lingkungan

Berdasarkan hasil analisis dengan menggunakan skala Likert tentang kelembagaan yang juga ikut berpartisipasi dalam pelestarian lingkungan, diperoleh skor rataan yang dimensinya sebesar 3,56 , berarti responden mempunyai persepsi yang baik dan setuju dengan pernyataan tersebut. Hal ini dikarenakan lembaga pemerintah, lembaga masyarakat, lembaga keagamaan, LSM dan lembaga swasta yang bersifat komersialpun ikut berpartisipasi dalam pelestarian lingkungan khususnya hutan mangrove, sehingga masyarakat merasa partisipasi dari kelembagaan baik dalam pelestarian hutan mangrove di Desa Tiwoho. Persepsi masyarakat 
terhadap pernyataan ini berada pada rentang yang positif.

10. Persepsi: PEMDA Sudah Menjalankan Tugas Pengelolaan Dalam Pengelolaan Hutan Mangrove Dengan Baik

Berdasarkan hasil analisis dengan menggunakan skala Likert tentang PEMDA yang sudah menjalankan tugas dalam pengelolaan hutan mangrove dengan baik diperoleh skor rataan yang dimensinya sebesar 3,56. Hal ini berarti responden mempunyai persepsi yang baik dan setuju dengan pernyataan tersebut. PEMDA sudah melakukan sosialisasi tentang pengelolaan hutan mangrove kepada masyarakat, PEMDA juga mengajak masyarakat untuk memelihara, menjaga dan melindungi hutan mangrove serta PEMDA mengalokasikan dana untuk pengelolaan hutan mangrove. Selain itu PEMDA juga mengajak lembaga lain untuk ikut andil dalam pengelolaan hutan mangrove. Persepsi masyarakat terhadap pernyataan ini berada pada rentang yang positif, terbukti dengan kondisi hutan mangrove yang sudah pulih, hijau dan rimbun.

Berdasarkan hasil analisis diketahui bahwa masyarakat Desa Tiwoho mempunyai persepsi yang positif terhadap pengelolaan hutan mangrove yang ada di desa mereka. Sebagai pembanding hasil penelitian yang dilakukan oleh Setiawan dkk (2017) tentang Persepsi dan Sikap Masyarakat Terhadap Konservasi Ekosistem Mangrove di Pulau Tanakeke Sulawesi Selatan. Hasil penelitian di sana menyatakan bahwa tingkat persepsi masyarakat sangat dipengaruhi oleh faktor tempat tinggal, pendidikan dan keikutsertaan masyarakat dalam kegiatan rehabilitasi mangrove, sedangkan tingkat sikap masyarakat sangat dipengaruhi oleh keikutsertaannya dalam kegiatan rehabilitasi mangrove. Hal ini berbeda dengan yang ada di Desa Tiwoho, persepsi masyarakat di Desa Tiwoho banyak dipengaruhi oleh keaktifan aparat dan tokoh masyarakat dalam memberikan sosialisasi kepada masyarakat.

\section{KESIMPULAN DAN SARAN}

\section{Kesimpulan}

1. Pengetahuan masyarakat terhadap fungsi dan manfaat hutan mangrove yang ada di-Desa Tiwoho 95\% sangat baik, hanya $5 \%$ masyarakat yang kurang mengetahui fungsi dan manfaat hutan mangrove. Pengetahuan masyarakat yang sangat baik tentang fungsi dan manfaat hutan mangrove ini tidak terlepas dari peran aktif pemerintah setempat dan tokoh masyarakat dalam mensosialisasikan fungsi dan manfaat hutan mangrove.

2. Persepsi masyarakat Desa Tiwoho terhadap pengelolaan hutan mangrove yang dinilai berdasarkan 10 kriteria hampir semua masyarakat mempunyai persepsi yang baik. Bahkan ada salah satu kriteria yang mempunyai persepsi sangat baik dan sangat positif dari masyarakat, mereka sangat setuju kalau pengelolaan hutan mangrove bukan saja tanggung jawab pemerintah melainkan tanggung jawab bersama. 


\section{Saran}

Perlu sosialisasi yang lebih intensif terhadap $5 \%$ masyarakat yang masih kurang mengetahui fungsi dan manfaat hutan mangrove agar masyarakat Desa Tiwoho $100 \%$ mengetahui fungsi dan manfaat hutan mangrove.

\section{DAFTAR PUSTAKA}

Kustanti, A. 2011. Manajemen Hutan Mangrove. Bogor (ID). PT. Penerbit Institut Pertanian Bogor.

Pahlevi, T. 2007. Persepsi Masyarakat Terhadap Taman Wisata Alam Sicikeh-Cikeh (Studi Kasus di Dusun Pancur Nauli, Desa Lae Hole II, Kec. Parbuluan, Kab. Dairi, Sumatera Utara). (Skripsi). Universitas Sumatera Utara.

Rahayu, W. M. 2010. Persepsi, Sikap dan Perilaku Masyarakat Terhadap Kelestarian Hutan (Studi Kasus di Desa Cinagara dan Desa Pasir Buncir Kecamatan Caringin, Kabupaten Bogor, Jawa Barat). (Skripsi). Bogor: Institut Pertanian Bogor.
Sarwono, Jonathan. 2009. Statistik Itu Mudah, Panduan Lengkap Untuk Belajar Komputasi Statistik Menggunakan SPSS 16. Yogyakarta: Penerbit Andi.

Sugihartono, dkk. 2007. Psikologi Pendidikan. Yogyakarta: UNY Press.

Sugiyono. 1994. Metode Penelitian Administrasi. Bandung: CV. Alfabeta.

Sugiyono. 2008. Metode Penelitian Kunatitatif Kualitatif dan R\&D. Bandung Alfabeta.

Sugiyono. 2013. Metode Penelitian Bisnis. Bandung: CV. Alfabeta.

Supriharyono. 2009. Konservâsi Ekosistem Sumberdaya Hayati di Wilayah Resisir dan Laut Tropis. Pustaka Pelajar. Yogyakarta.

Suwandhi, I. Heryadi, C. 2007. Hutan Bakau Manfaat Bagi Lingkungan dan Kehidupan manusia. Sinergi Pustaka Indonesia. Bandung.

Yuliasamaya, Darmawan, A. dan Hilmanto, R. 2014. Perubahan Tutupan Hutan Mangrove di Pesisir Kabupaten Lampung Timur. Jurnal Sylva Lestari. 


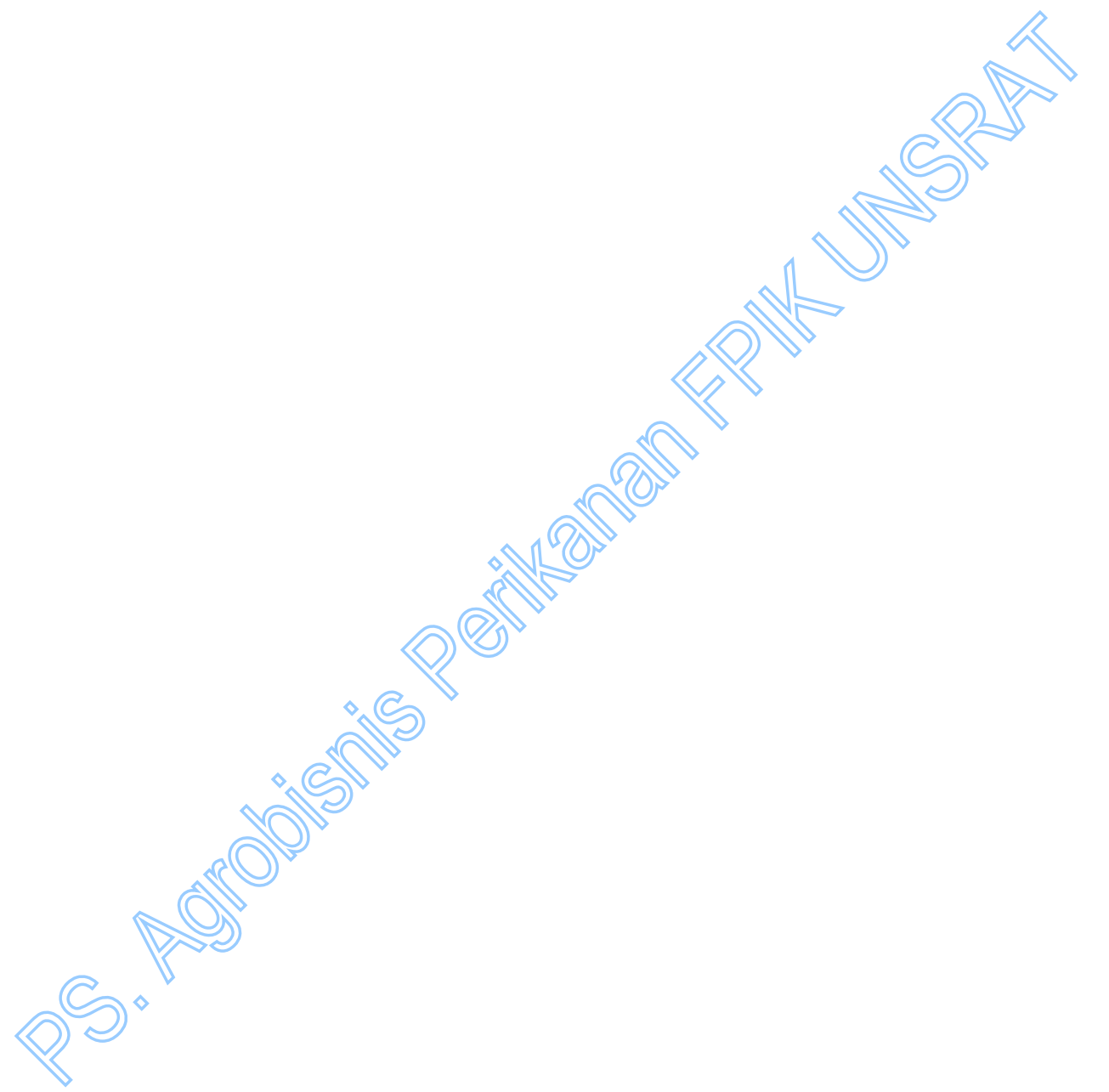

